mortality is greatly increased. ${ }^{67}$ In one series the perinatal mortality rate for delivery at home and in general-practitioner units was 9 per 1,000 , but the rate for those transferred was 82 per 1,000 . These challenging contrasts occurred in a region (Oxford) which at the time had the lowest maternal mortality in England and Wales, was expanding its generalpractitioner units, and had implemented the concepi of area departments in which every practitioner unit was integrated, functionally though not always geographically, with a consultant unit. When emergency help is needed, distance means time, and time can mean death. These are the reasons why both royal colleges agree that physical and clinical integration of specialist and general-practitioner beds is the ideal, and team work is essential. To facilitate these developments it becomes increasingly urgent for representatives of both consultants and general practitioners to get together and agree on mutually acceptable plans. The extent of the agreement which already exists, as shown by the reports from the two colleges, augurs well for the meeting.

\section{Unintentioned Impact}

Last week the British Broadcasting Corporation screened a programme by its Horizon team called " Doctor's Dilemma." It dealt with the toxic side-effects of drugs, and was on B.B.C.2 at 8 p.m., a peak viewing time. Horizon, according to the Radio Times, was setting out to answer these questions: How are we trying to avoid another thalidomide tragedy? Are we technically equipped to assess (and avoid) the possible harm of the contraceptive pill ? Are we using antibiotics indiscriminately so that in the future we may regress to the pre-antibiotic era? All these are questions which deserve examination, and to which the public has an undoubted right to an honest answer. What is far less certain is whether such an inquiry can be done satisfactorily on a mass medium like television.

The intentions of the programme were exemplary. "For half a century," said the narrator, speaking of the therapeutic revolution, "it has been a success story." The audience saw quick takes of diseases such as leprosy and yaws before and after treatment. But then came the first shock: a woman who had been cured of her intestinal tuberculosis by streptomycin but left atoxic. Although only 55, she was in an old people's home. She was seen staggering along a pavement, and, interviewed, said that she could not work, became sick when she travelled, and was no longer an independent person. Visually the impact of this one case erased most of what had preceded it. The lesson that drugs can be extremely harmful was rammed home by a sequence showing thalidomide children. The stage set, the programme then got into its stride. The screen showed the toxicity-testing of drugs in pharmaceutical laboratories, and viewers were treated in turn to the tranquillizing of fighting fishes, the slicing of a frozen rat for autoradiographic tracing of a drug's metabolic progress, the extraction of rat foetuses for examination to exclude deformity, and, of all things, rabbits in wooden pillories having their rectal temperatures taken. No wonder one approving journalist wrote the next day that he had watched the programme "by turns nauseated and fascinated." It was fair comment.
It had to be admitted, however, that animals are the weak link in the chain of testing, "since no animal will respond to a drug in the same way as man." So from animals the programme moved to humans-volunteers on the contraceptive pill, in whom, viewers learnt, a diabetic type of glucosetolerance curve had developed. Next a clinical pharmacologist warned what may happen if drugs interact with each other in the body, or with foodstuffs-a point forcefully made on the screen by a controlled experiment with two rats, the one injected with food substance as well as antidepressant reacting as if to a prolonged electric shock. It was left to a psychiatrist who believes firmly in the value of antidepressants to try to redress the balance and justify the risks of using them. He said his piece and his patient gave a glowing testimonial, but by then only the more judicial of their audience would have been accessible. The remainder of the 40-minute programme concerned less disturbing questions. The transfer of bacterial resistance to antibiotics and the role in this of adding these drugs to animal feeds were well presented. The programme ended by glancing at how information about drugs reaches doctors and at some of the ways they can be helped to evaluate it.

Television programmes on medicine impose a responsibility on their producers which goes well beyond providing good television. Equally doctors taking part in them must realize how easily cutting or rearrangement can distort what they hope to convey, and their appearance may be taken as tacit assent. The audience is vast, and truly described as captive. It includes the sick as well as the healthy, the simple as well as the sophisticated. The side-effects of drugs, especially when directly linked to the emotive thalidomide tragedy, make an explosive mixture. The illustrations of their ill-effects on the Horizon programme were far more dramatic than those of their benefits. No doctor would wish to transfer even a part of his daily dilemma to his patients, but this is what this programme did.

\section{Allergy to Influenza Vaccine}

To meet the outbreak of Hong Kong A2 influenza expected this winter $^{1}$ many persons will seek immunization against it. During the last few years it has been shown that influenza vaccine gives immunity for at least six months to about $75 \%$ of people vaccinated, and many regard this as worthwhile protection, particularly for patients in whom the disease may lead to more serious sequelae. Though the Hong Kong virus is an A2 strain, it is sufficiently removed antigenically from those infecting our community in recent years for few people to have any natural immunity to it. The epidemic in the Far East occurred too late for the strain to be included in the vaccine produced earlier for use this winter. Accordingly, two vaccines will be available-the one containing representative strains of recent $A 2$ and $B$ influenza viruses and the other a monovalent vaccine containing only the A2 Hong Kong strain or an isolate of similar antigenic character.

A question to be considered is whether influenza vaccine carries a risk of sensitization to egg proteins contained in it. $^{2}$ The virus is grown by infecting the allantoic cavity of embryonated hens' eggs and, after incubation for two days,

1 Brit. med. f., 1968, 3, 757.

2 Davies, N. N.. Brit. med. $\mathcal{F}$., 1968, 4, 327. 
harvesting the allantoic fluids. Ten years ago the virus was inactivated with formaldehyde and little attempt was made to purify the product. But technical developments during the last five years have contributed greatly to the purity of the vaccine, and turbid fluids have been replaced by slightly opalescent virus suspensions. The egg proteins are removed during the purification processes, and vaccines available today contain only traces of material likely to sensitize the patient. Indeed, an upper limit has been placed on the quantity of protein nitrogen allowed in the vaccine. Nevertheless, since the virus is grown in hens' eggs the vaccine is best not given to persons with a history of allergic disease, in particular of sensitivity to hens' eggs. It is most unlikely that a normal person would have an allergic reaction to the influenza vaccines available this winter, and highly improbable that anyone would become sensitized to hens' eggs by being given a single dose of vaccine. On balance the protection given by influenza vaccine far outweighs the risk of reactions occurring in normal non-allergic people.

\section{Squatting in Fallot's Tetralogy}

Children with the tetralogy of Fallot soon discover the symptomatic relief obtained by squatting after exercise. Indeed, the trick is probably usually learnt in infancy when they adopt a knee-chest posture. Helen Taussig ${ }^{1}$ was the first to give a full description of the phenomenon of squatting, and it is particularly interesting that, in speculating about the mechanism of relief given to patients in this way, she quoted the words of a 10-year-old patient, "It cuts off the circulation to my legs and increases the circulation to my lungs." Since that time there has been considerable controversy about the exact way in which squatting affects the circulation in these patients. W. F. Hamilton and his colleagues ${ }^{2}$ emphasized the importance of the rise in systemic vascular resistance that occurs during squatting, claiming that this would increase the relative flow into the pulmonary artery. They also stated, without clear evidence, that squatting increased the systemic venous return, and subsequently other authors ${ }^{3-5}$ have argued on similar lines. Nevertheless, L. Brotmacher, ${ }^{6}$ using plethysmography and oximetry, concluded that squatting actually decreased the venous return from the legs, though he was unable to measure venous flow directly.

Recently W. G. Guntheroth and his colleagues have measured directly the flow in the inferior vena cava in patients with Fallot's tetralogy. They have confirmed Brotmacher's conclusion about diminished venous return during squatting, and have also shown that there is a sustained decrease in flow in the inferior vena cava in the knee-chest position adopted during squatting after exercise. This is accompanied by a rise in systemic arterial pressure and a

\footnotetext{
1 Taussig, H. B., Congenital Malformation of the Heart, 1960, Vol. 2, 2nd ed., p. 23. Cambridge, Mass.

2 Hamilton, W. F., Winslow, J. A., and Hamilton, W. F., jun., f. clin. Invest., 1950, 29, 20.

3 Nadas, A. S., Pediatric Cardiology, 1963, 2nd ed., p. 353. Philadelphia.

4 O'Donnell, T. V., and McIlroy, M. B., Amer. Heart f., 1962, 64, 347.

5 Sharpey-Shafer, E. P., Brit. med. F., 1956, 1, 1072.

- Brotmacher, L., Brit. Heart f., 1957, 19, 567. ' Guntheroth, W. G., Mortan, B. C., Mullins, G. L., and Baum, D.,
Amer. Heart f., 1968, 75, 313 .
}

rise in arterial oxygen saturation, which had fallen to low levels during exercise.

Guntheroth and his co-workers point out that these phenomena may be understood by considering what has been happening during the exercise immediately preceding squatting. A large oxygen debt has built up, the muscle vascular beds are dilated and remain so after exercise, and there is increased extraction of the available oxygen locally, so that oxygen saturation of the venous blood is further reduced. Since in Fallot's tetralogy some of the venous return to the right heart passes directly into the aorta, any reduction in the venous oxygen saturation leads directly to a reduction of the arterial saturation as well. The vasodilatation in the exercised limbs lowers the total systemic vascular resistance, and hence there is also a fall in blood pressure. Squatting helps to counteract these effects in two main ways. Firstly, by diminishing the blood flow to the legs it helps to maintain the peripheral vascular resistance, and hence more of the cardiac output is directed into the lungs. Secondly, by allowing the oxygen debt after exercise to be paid off over a longer period it corrects the precipitous fall in arterial oxygen saturation that has accompanied exercise. Helen Taussig's patient was right.

\section{Racial Harmony}

Last week Mr. Enoch Powell again spoke on racial issues in a manner apt to inflame opinion on problems that above all at this time need dispassionate thought. His views have evoked energetic public discussion, and it is not the task of the B.M.f. to add to it. But the subject of his speech, race relations, is something that concerns the medical profession, for the humane nature of medicine and its international connexions make it stand as plainly opposed as could be to racial prejudice and conflict.

In one sense this goes without saying. The public face of medicine in Britain has always been firmly set against any kind of discrimination. But from time to time the B.M.F. office does receive letters from doctors who believe they have been unfairly treated because of their colour. It should be emphasized that such complaints are rare: it is simply regrettable that they should have any cause for utterance at all. Nor is it always certain that the treatment of which a reader may complain had anything to do with his colour or race as such, though occasionally that would seem to be the inescapable inference. Sometimes it would seem to have been more the result of his simply being a foreigner. And it must be admitted that, in addition to the usual difficulties a foreigner may experience in gaining acceptance in any country, a certain coldness or brusqueness is sometimes noted in Britons when dealing with a stranger. It springs perhaps from social reserve and as a cause of offence is wholly unintentional. But it is a poor companion to that scrupulous politeness and even positive desire to help on which visitors to these shores sometimes comment with gratitude.

This country owes a debt to the hosts of doctors and nurses, many of them coloured, who have come here for training or to find a permanent home. To these colleagues, our fellow physicians and surgeons, we owe an obligation of working in complete harmony. Evidence of any departure from it is rare-and should be absent. 